Владимирова Т.B.

\title{
НОВЫЕ СОЦИАЛЬНЫЕ МОБИЛЬНОСТИ КАК ПРАКТИКИ ОБЕСПЕЧЕНИЯ ИНФОРМАЦИОННОЙ БЕЗОПАСНОСТИ
}

\begin{abstract}
Аннотация: В статье в контексте практик обеспечения информационной безопасности рассматриваются новые социальные мобильности. Сочиальный субъект, обеспечивающий информационную безопасность, с одной стороны, осуществляет защиту информации и защиту от информации, с другой стороны, развивает ориентацию во внешней информационной среде, поскольку его ресурсы, в условиях подвижности социальной среды, должны всякий раз обновляться. При этом обновление информационных ресурсов субъекта происходит с нарастающей интенсивностью, сообразно нарастанию интенсивности информационных потоков, что, в свою очередь, ведет к росту устаревания информации. В таких условиях практики мобильностей являются практиками безопасности. Теоретико-методологическим основанием исследования являются соииально-философские и социологические теории. В частности, используются идеи соииологии мобильностей Дж. Урри, теория «объектиентрированной сочиальности» К. Кнорр Цетины. Практики новых мобильностей, составляющие сегодня сетевую и потоковую морфологию соииального мира, рассматриваются автором как общие практики обеспечения информационной безопасности. Представление об их организации частично раскрывается через понятия каналов, туннелей и потоков (Дж. Урри). Автор отмечает, что новые мобильности необходимо осмысливать и использовать как практики обеспечения информационной безопасности национальных сил в условиях роста потоков и сетей. Сущностным аспектом новых мобильностей является высокая интенсивность коммуникаций, выраженная в скорости и многообразии взаимодействия. Отмечается, что характерным элементом новых мобильностей является объектуализация отношений или появление «объектиентрированной соџиальности» (К. Кнорр Цетина).
\end{abstract}

Review: The article concerns new social mobilities in terms of practices of informant security enforcement. A social actor responsible for information security, on one hand, provides for protection of information and protection against information and, on the other hand, develops the orientation at the external information environment because his resources need to be constantly renovated under the conditions of changing social reality. In these circumstances the intensity of renovation of information resources is constantly increasing according to the growing intensity of information flows which, in its turn, leads to faster deterioration of information. In these circumstances the mobility practices are good security practices. Theoretical and methodological basis of the research includes social-philosophical and sociological theories. In particular, T. Vladimirova uses the concept of social mobility offered by John Urry and the theory of the object-centered sociality introduced by Karin Knorr-Cetina. New mobility practices that constitute today's network and flow mythology of the social world are viewed by the researcher as general practices of information security enforcement. The concept of their organization is partially revealed through the ideas of channels, tunnels and flows in John Urry's works. T. Vladimirova notes that new mobilities need to be understood and used as practices of information security enforcement of national forces under the conditions of a growing number of flows and networks. The essential aspect of new mobilities is a high intensity of communication demonstrated in the pace and variety of interactions. Noteworthy that a typical attribute of new mobilities is the objectualization of relations and the appearance of the 'object-centered reality' (Karin Knorr-Cetina's term).

Ключевые слова: Практики новых мобильностей, обеспечение информационной безопасности, высокая интенсивность коммуникации, объектиентрированная соииальность, каналь, туннели, потоки, сети, общие практики безопасности, сетевые практики безопасности.

Keywords: New mobility practices, information security enforcement, high intensity of communication, object-centered sociality, channels, tunnels, flows, networks, general security practices, network security practices. 
Д ж. Урри отмечает, что в будущем понятие общества будет особенно широко применяться теми могущественными «национальилами», которые пытаются усмирять, контролировать и регулировать мощные сети и потоки, пересекающие их проницаемые границы ${ }^{1}$. Для него, как и для многих других западных социологов, важна мысль о том, что с ростом сетей и потоков общество как понятие, указывающее на некую социальную локальность, утрачивает значение.

Под «национальными силами» мы понимаем государства, которые вынуждены «усмирять, контролировать и регулировать», поскольку выполняют свою извечную функцию - обеспечение безопасности общества, локального и самобытного. По мысли Дж. Урри сети и потоки, осуществляются практиками новых горизонтальных мобильностей. Именно эти практики становятся центральной категорией новой социологии - социологии мобильностей.

Социальные мобильности, вовлекающие множество различных технологий и объектов, проблематизируют устойчивость и безопасность общества. Дж. Урри отмечает, что «социальная управляемость», в какой-то мере, поставлена под вопрос мобильностями, организованными в сложно структурируемых временных и пространственных координатах. Под мобильностями Дж. Урри подразумевает как географические, так и социальные феномены, и обращается в большей мере к горизонтальной мобильности. С другой стороны, он предлагает исследовать пределы, диапазон и разнообразные эффекты физической, виртуальной и воображаемой мобильности людей. Он считает, что социология мобильностей должна развиваться вслед за социологией объектов с тем, чтобы сохранять адекватность в изучении современности. Для него «различные потоки объектов, проникающие сквозь социетальные границы, и их пересечения с множественными потоками людей чрезвычайно значимы» ${ }^{2}$.

Мы поддерживаем тезис Дж. Урри о чрезвычайной значимости новых горизонтальных мобильностей. Она заключается в том, что в условиях роста интенсивности информационных

\footnotetext{
${ }^{1}$ Урри Дж. Социология за пределами обществ: виды мобильности для XXI столетия /пер. с англ. Д. Кралечкина; Нац. исслед. ун-т «Высшая школа экономики» - 2012. - С. 10.

${ }^{2}$ Там же. С. 12.
}

процессов субъекту необходимо сохранять адекватность внешнему миру, а значит, в выработке практик безопасности, обращаться к обретению знания и навыков мобильностей.

Национальные силы (государства), преследуя цели обеспечения безопасности своих обществ, сталкиваются с нивелирующей и разрушающей силой информационных сетей и потоков. «Потоки действуют опустошающее на существующие общества, в частности, за счет избыточного количества возникших «социаций», ставящих своей целью отражать, оспаривать, уклоняться, предлагать альтернативы или отстаивать различные потоки, часто выходящие за пределы социетального «региона». Как следствие, внутри каждого существующего «общества» устанавливается сложный, смещенный, дизъюктивный порядок, порядок рассредоточенности, порожденный постоянным комбинированием и рекомбинированием множественных потоков во времени и пространстве, зачастую без всякой связи с регионами существующих обществ, но лишь следующий некоей гипертекстуальной схеме. ... Описанные конфигурации ослабляют способность сициетально сплачивать своих граждан, принимать политические решения от имени общества в целом, обеспечивать национальной идентичностью и озвучивать единогласное мнение национального государства ...»³.

Потоки и сети (глобальные метасети) способны подчинять большие группы людей. Сегодня все чаще человек связывает свою профессиональную деятельность, образование, досуг, пользование услугами с социальными сетями и с сетевыми организационными структурами. С развитием сетевого коммуникативного пространства образуется разрыв между сетевым принципом организации и традиционной управленческой деятельностью. Территориальные организационные структуры начинают претерпевать серьезные реконструкции. Частично они становятся дисфункциональными. И. А. Василенко отмечает, что отдельные виды политической деятельности не исчезают, а исчезает их прежнее структурное значение в поле социального, политического управления, оно переходит в новую логику информационного сетевого пространства ${ }^{4}$ В литературе (М. Кастельс, С. Лэш, У.

\footnotetext{
${ }^{3}$ Там же. С. $58-59$.

${ }^{4}$ См. Василенко И. А. Политическая философия: Учебное пособие / И. А. Василенко. - М.: Гардарики. 2004.
} 


\section{Политика и общество 8 (116) • 2014}

Бек, Дж. Урри, В. Л. Иноземцев, Д. В. Иванов, И. А. Василенко и др.) мы часто можем встретить утверждение, что власть в условиях информационного, сетевого общества уже не является монополией института государства и политических партий. Она распространяется по глобальным сетям богатства, информации и имиджей, которые циркулируют и видоизменяются, не привязанные к какомулибо одному географическому месту. Новая власть заключается в информационных кодах, в представительских имиджах. На их основе общество организует свои институты, а люди выстраивают свои действия. Современное социальное пространство начинает формироваться по новым правилам и принципам политической игры, которые диктует специфика информационных, сетевых технологий.

«Между тем, наше политическое зрение так привыкло к сакраментальным политическим организациям - к трем ветвям политической власти, к государственным структурам, к ярким знаменам и лозунгам политических партий, что мы испытываем вполне понятное чувство растерянности перед виртуальными формами политической борьбы, перед натиском информационной агрессии, перед стремительно расширяющимся миром символов». ${ }^{5}$ Сравнительно недавно российское общество приступило к решению серьезнейшей задачи - построению основных демократических институтов. Мы сталкиваемся с парадоксом: с одной стороны в России начинают развиваться и набирать силу институты политической демократии, с другой стороны, они перестают играть главную роль в жизни общества еще не сформировавшись. Информационное общество демонстрирует противоречивую тенденцию: чем современнее становится общество, тем большее значение в нем придается не институтам и социальным нормам, а самим действующим лицам и их имиджам, разворачивающимся в сетевом пространстве, причем на виртуальной политической сцене. ${ }^{6}$

Действительно, каким образом в условиях развития сетевых коммуникаций, в условиях виртуализации социального пространства возможно культивировать и формировать определенные социальные ценности в обществе, и, соответственно, способствовать воспроизводству определенных социаль-

\footnotetext{
${ }^{5}$ Там же. С. 15.

${ }^{6}$ См. там же.
}

ных норм, а значит, и социально-политической системы общества, форм власти? Возможно ли это в обществе, где, все сложнее традиционным механизмам управления соперничать с возможностями людей, опирающихся на ресурсы информационных сетей? Конечно, подобный спектр вопросов нельзя формулировать как непосредственные угрозы для данного общества. Но видение одной из важнейших проблем современности, связанной с ростом сетей и потоков, необходимо.

На наш взгляд, сегодня необходимым является формирование понимания проблемы информационной безопасности в предметном поле социологии безопасности. Социологический анализ сетевых коммуникаций, информационных потоков, с точки зрения безопасности личности, общества и государства является перспективным направлением в становлении теории безопасности. Современный мир столкнулся с удвоением социальной реальности - с появлением виртуальной реальности, где актор получает наибольшую свободу действия ${ }^{7}$. Отсутствие компетенций в сфере определения и прогнозирования информационных процессов, движения потоков и сетей ведет к обострению проблемы информационной безопасности. Социальная реальность, структурируемая сетевыми коммуникациями, не знает ограничений, сформированных традиционными социальными нормами, это мир, лишенный социального порядка в традиционном его понимании. С другой стороны, это ускользающий мир (Э. Гидденс), глобальная текучая среда (Дж. Урри) где интенсивность и многообразие коммуникаций всякий раз возрастает, отдаляя возможности его адекватного осмысления.

На наш взгляд, важно, чтобы новые практики мобильности, позволяющие процветать в условиях хаоса и неопределенности, начали осмысливаться и использоваться как практики обеспечения информационной безопасности национальных сил в условиях всепоглощуающей глобализации.

Об обеспечении информационной безопасности можно говорить в широком и узком смысле

\footnotetext{
${ }^{7}$ См. Владимирова T. В. Развитие структур накопления и ускорения девиации как условие безопасности общества // Журнал Социологии и социальной антропологии - T. XV № 2, - 2012. - С.129 - 146; Владимирова Т.В. Сетевые коммуникации как новая «формула спасения» социального порядка // Национальная безопасность - Nota bene. 2013. № 2 (25). - C. 371-378. - DOI: 10.7256/2073 -8560.2013.02.16.
} 
этого слова: информационная безопасность в условиях современного общества (актуальной социальной реальности потоков и сетей) и информационная безопасность в условиях киберпространства (виртуальной социальной реальности). В первом случае, и в целом, речь идет о социальных практиках, адекватных скорости и многообразию современных коммуникаций. ${ }^{8}$ Во втором случае, речь идет о сетевых практиках, адекватных изменчивому виртуальному пространству сетей и потоков. Второй тип практик обеспечения информационной безопасности составляет частный случай первого. И первый тип, и второй тип социальных практик сводятся, к содержанию:

1. защиты субъектом своей информации и защиты от внешней информации;

2. к ориентации в информационном пространстве, поскольку ресурсы в условиях роста устаревания информации должны всякий раз пересматриваться и обновляться.

Наш подход к понятию информационной безопасности задает как бы социальный внешний контур представлений об обеспечении безопасности субъекта. Этот контур очерчивает традиционное, прежнее (более технологическое) определение информационной безопасности, суть которого заключается в «защите информации и защите от информации». ${ }^{9}$

Сети, каналь, потоки - с этими понятиями работает Дж. Урри, предпринимая попытку новой концептуализации социального мира «за пределами обществ». Дж. Урри приводит определение М. Кастельса: «Сеть - совокупность связанных узлов, в которой расстояние между социальными позициями короче там, где такие позиции являются узлами конкретной сети, а не лежат за ее пределами. Сети следует рассматривать в качестве динамичных открытых структур, способных

\footnotetext{
${ }^{8}$ См. Владимирова Т.В. Информационная безопасность: к методологическим основаниям анализа вопроса // Информационное общество № 5, 2012 г. С. 47 - 52; Владимирова Т.В. Информационная безопасность: социологическая перспектива понятия // Национальная безопасность. - Nota bene. 2013. № 4 (27). - C. 597- 604. DOI: 10.7256/20738560.2013.4.7476.

${ }^{9}$ Владимирова Т. В. Интенсивность коммуникаций практик новых мобильностей и информационная безопасность // NB: проблемы общества и политики - 2014. - № 1. - С. 89 - 111. DOI: 10.7256/2306-0158.2014.1.10918. URL: http://e-notabene. $\mathrm{ru} / \mathrm{pr} /$ article_10918.html
}

осуществлять коммуникацию с новыми узлами и эволюционировать» ${ }^{10}$.

Сетевые практики, на наш взгляд, сами по себе являются сегодня первыми из практик обеспечения интересов субъекта, соответственно, практиками обеспечения безопасности. Представление об организации практик мобильностей частично раскрывается Дж. Урри через понятия каналов, туннелей и потоков. Каналь - это сети машин, технологий, организаций, текстов и акторов, образующие различные взаимосвязанные узлы, через которые могут передаваться потоки. Каналы преобразуют измерения времени и пространства. Дж. Урри называет следующие из них:

- транспортировка людей воздушным, морским путем, по железным дорогам, автомагистралям и иным путям;

- транспортировка объектов через почтовые и другие системы;

- проволочные и коаксиальные кабели;

- микроволновые каналы, используемые сотовыми телефонами;

- радио-и телевизионные спутники;

- оптоволоконный кабель для телефонии, телевидения и компьютеров.

После появления того или иного канала индивиды и прежде всего корпорации внутри каждого общества, как правило, предпринимают попытки подключиться к ним через превращение самих себя в узлы данной сети. ${ }^{11}$

Для нас важно замечание Дж. Урри о том, что в противоположность неравенства покоя создаются новые неравенства потоков, приобретающие форму «туннелей». ${ }^{12}$ Он приводит утверждения Грэма и Марвина, которые считают, что в мире происходит сворачивание времени и пространства продвинутыми телекоммуникационными и транспортными структурами, где каналы, минуя одни области, соединяют другие плотными в информационном и транспортном отношении «туннелями» (Graham, Marvin, 1996. Р. 60). Поскольку потоки неравны (вероятно по своим скоростным характеристикам и степени насыщенности), неравными являются

\footnotetext{
${ }^{10}$ Урри Дж. Социология за пределами обществ: виды мобильности для XXI столетия /пер. с англ. Д. Кралечкина; Нац. исслед. ун-т «Высшая школа экономики» - 2012. - С. 54.

11 Там же. C.56.

12 Там же С. 57.
} 


\section{Политика и общество 8 (116) • 2014}

возможности субъектов, которые задействованы в разных потоках.

Дж. Урри отмечает, что некоторые каналы функционируют на глобальном уровне. В этот процесс вовлечены основные международные организации. В отличие от структурированных каналов, потоки состоят из людей, образов, информации, денег и отходов, которые движутся внутри, а главное, поверх национальных границ, причем отдельные общества зачастую неспособны или не желают контролировать их ни прямо, ни косвенно. Потоки создают новые неравенства «доступа - отсутствия доступа», которые не фиксируются в юрисдикциях отдельных государств. ${ }^{13}$

Для социальных субъектов сети, каналы, потоки создают как новые возможности, так и новые риски и угрозы, требующие актуализации практик информационной безопасности. Подобное усложнение жизни определяет появление новых особенностей социальных практик в обществе. В социальной теории такие особенности фиксируются в терминах «скорости и временности социальной ситуации», «степени проходимости социальных ситуаций» (Э. Тоффлер), «отношения ограниченного участия» (Э. Тоффлер, 3. Бауман, С. Леш и др.), «дальнодействия и отвлеченности» (В. Е. Кемеров), «объектуализации отношений или появления «объектцентрированной социальности» (К. Кнорр Цетина), «делокализации социальных действий, их извлечения из конкретного контекста и свободного перемещения в самых широких пространственно-временных рамках»; «контрфактуальность мышления и калькуляция рисков» (Э. Гидденс), «частично-непрерывное внимание» и «пост-многозадачное поведение, характеризующее стремление индивида быть живым узлом коммуникационной сети» (Л. Стоун). ${ }^{14}$ В целом, все эти особенности практик мы объединяем все тем же термином «новые социальные мобильности», который является основополагающим в социологии мобильностей Дж. Урри.

Обратимся к одной из особенностей современных практик, которые мы называем новыми мо-

\footnotetext{
13 Там же. С. 57.

${ }^{14}$ Владимирова Т. В. Интенсивность коммуникаций практик новых мобильностей и информационная безопасность // NB: проблемы общества и политики - 2014. - № 1. - С. 89 - 111. DOI: 10.7256/2306-0158.2014.1.10918. URL: http://e-notabene. $\mathrm{ru} / \mathrm{pr} / \mathrm{article}$ _10918.html
}

бильностями. Объектуализация отношений или появление «объектцентрированной социальности» (К. Кнорр Цетина) является характерным элементом новых социальных мобильностей. Работа с информацией, знанием в современном обществе становится не выбором, а необходимостью. В условиях такой необходимости, социальные субъекты для реализации и защиты своих интересов, задают иные формы отношения с миром. К. Кнорр Цетина считает, что распространение экспертных контекстов и культур знания в обществе являются возможным фактором роста объектно-центрированной социальности. Повсеместное присутствие таких культур как «личности эксперта», «объектов, обладающих свойствами объектов знания», подразумевают перегруппировку социальных отношений вокруг объектов знания. «Объектцентрированная реальность» - это социальная форма, которая представляет собой оборотную сторону современного опыта индивидуализации. Объектно-центрированная среда определяет идентичность так же как ранее ее определяли сообщество и семья. ${ }^{15}$ Другими словами, такая среда все в большей мере определяет интересы индивида или является гарантом реализации его интересов, их безопасности. Суть процесса «объектуализации» заключается в том, что объекты замещают людей как партнеров по взаимодействию и все в большей мере опосредуют человеческие отношения, делая последние зависимыми от них. Под объектами следует понимать предметы исследовательской деятельности и инструменты этой деятельности. «Объектцентрированные» отношения характеризуются переплетением социального в его привычном значении с «другими культурами». Такой другой культурой является знание и экспертиза.

Усиление роли экспертных систем выражается не только в широком присутствии технологических и информационных продуктов знания. Оно предполагает существование связанных со знанием структур и форм включенности. Новое состояние общества К. Кнорр Цетина называет обществом знания и отмечает, что это не просто общество с большим количеством экспертов, технологических и инфор-

\footnotetext{
${ }^{15}$ См. Кнорр Цетина К. Объектная социальность: общественные отношения в постсоциальных обществах знания // Журнал социологии и социальной антропологии. $-2002 .-\mathrm{T}$. V. - № $1 .-$ С. $22-47$.
} 
мационных инфраструктур и интерпретаций специалистов, а не участников, скорее, это общество, где культуры знания органически вплетены в ткань общества, как и целый ряд процессов, практик отношений, обслуживающих знание. ${ }^{16}$ Идея объектуализации предполагает, что мы переживаем переход от социальной и нормативной интеграции к объектам как партнерам по отношениям или компонентам включающей среды. Такое понимание вовсе не отрицает того факта, что определенные формы связи с объектами и посредством их существовали всегда. К. Кнорр Цетина утверждает, что именно эти формы становятся преобладающими в «постсоциальных обществах знания».

Для нас примечательно, что К. Кнорр Цетина указывает на фактор возрастания рисков, который, в том числе, управляет процессами объектуализации. Объекты могут рассматриваться как своего рода средства преодоления рисков и неудач, заключенных в человеческих отношениях. В частности, поскольку многие объекты повседневной жизни превращаются в высокотехнологичные приспособления, некоторые из свойств, демонстрируемых объектами в экспертных контекстах, могут привноситься в повседневную жизнь, превращая инструмент или товар в повседневную эпистемическую вещь ${ }^{17}$, обеспечивающую безопасность реализации интереса.

\section{Выводы}

Итак, практики мобильностей, составляющие сегодня новую сетевую и потоковую морфологию социального мира, рассматриваются нами как общие практики обеспечения информационной безопасности. Национальные силы (государства), преследуя цели обеспечения безопасности своих обществ, сталкиваются с нивелирующей и разрушающей силой информационных сетей и потоков. Сегодня важно, чтобы мобильности, позволяющие процветать в условиях хаоса и неопределенности, начали осмысливаться и использоваться как практики обеспечения информационной безопасности национальных сил в условиях роста потоков и сетей.

Сетевые практики, на наш взгляд, сами по себе, являются первыми в числе общих практик в защите интересов субъекта. Представление об их организации частично раскрывается Дж. Урри через понятия каналов, туннелей и потоков.

Важным аспектом новых социальных мобильностей как практик обеспечения безопасности является высокая интенсивность коммуникаций, выраженная в скорости и многообразии взаимодействия. Чем выше уровень интенсивности (скорости и разнообразия) коммуникаций, осуществляемых субъектом, тем в большей безопасности он пребывает в смысле защищенности своих интересов в условиях роста информационных потоков и устаревания информации. Высокая интенсивность коммуникаций обеспечивается такой характеристикой новых мобильностей как объектуализация отношений или «объектцентрированной социальностью» (К. Кнорр Цетина). Объекты могут рассматриваться и как своего рода «средства преодоления рисков и неудач, заключенных в человеческих отношениях», и как средства обеспечения безопасности во взаимодействии с информационной средой.

\section{Библиография:}

1. Урри Дж. Социология за пределами обществ: виды мобильности для XXI столетия /пер. с англ. Д. Кралечкина; Нац. исслед. ун-т «Высшая школа экономики»-2012. - С. 10.

2. Василенко И. А. Политическая философия: Учебное пособие / И. А. Василенко. - М.: Гардарики. 2004.

3. Владимирова Т. В. Развитие структур накопления и ускорения девиации как условие безопасности общества // Журнал Социологии и социальной антропологии-Т. XV-№ 2,-2012. - C.129-146;

4. Владимирова Т.В. Сетевые коммуникации как новая «формула спасения» социального порядка // Национальная безопасность / nota bene. 2013. № 2 (25). - C. 371-378. - DOI: 10.7256/2073-8560.2013.02.16.

5. Владимирова Т.В. Информационная безопасность: к методологическим основаниям анализа вопроса // Информационное общество № 5, 2012 г. С. 47 - 52;

\footnotetext{
${ }^{16}$ Там же. С. 109.

${ }^{17}$ Там же. С. 121.
} 


\section{Политика и общество 8 (116) • 2014}

6. Владимирова Т.В. Информационная безопасность: социологическая перспектива понятия // Национальная безопасность / nota bene. 2013. № 4 (27). - C. 597-604. DOI: 10.7256/2073-8560.2013.4.7476.

7. Владимирова Т. В. Интенсивность коммуникаций практик новых мобильностей и информационная безопасность // NB: проблемы общества и политики - 2014. - № 1. - C. 89-111. DOI: 10.7256/2306-0158.2014.1.10918. URL: http:// e-notabene.ru/pr/article_10918.html Кнорр Цетина К. Объектная социальность: общественные отношения в постсоциальных обществах знания // Журнал социологии и социальной антропологии. - 2002. - Т. V. - № 1. - С. 22 - 47.

8. Урри Дж. Мобильности / пер. с англ. А.В. Лазарева, вступ. статья Н.А. Харламова. - М.: Издательская и консалтинговая группа «Праксис», 2012.

9. Владимирова Т.В. Проблема устойчивости порядка как угроза безопасности // NB: Национальная безопасность. 2013. - 2. - C. 67-87. DOI: 10.7256/2306-0417.2013.2.590. URL: http://www.e-notabene.ru/nb/article 590.html

10. Бахтин С.А. Интернет-экономика - новый вызов национальной экономической безопасности: общая характеристика // Национальная безопасность / nota bene. - 2012. - 6. - С. 118-122.

11. Владимирова Т.В. К социальной природе понятия «информационная безопасность» // NB: Национальная безопасность. - 2013. - 4. - С. 78-95. DOI: 10.7256/2306-0417.2013.4.596. URL: http://www.e-notabene.ru/nb/article_596.html

12. Владимирова Т.В. Рост «потребности в Неотрицаемом» и безопасность общества // NB: Национальная безопасность. - 2013. - № 3. - C.136-157. DOI: 10.7256/2306-0417.2013.3.595. URL: http://e-notabene.ru/nb/article_595.html

13. С.А. Бахтин Интернет-экономика - новый вызов национальной экономической безопасности: общая характеристика // Национальная безопасность / nota bene. - 2012. - 6. - С. 118-122.

14. Царегородцев А.В., Ермошкин Г.Н.. Базовые принципы построения дерева целей информационной безопасности среды облачных вычислений. // Национальная безопасность / nota bene. - 2013. - № 5. - C. 69-79. DOI: $.10 .7256 / 2073-8560.2013 .5 .9583$.

15. А.В. Костина, Г.П. Хорина. Информационная культура в концепциях информационного общества. // Философия и культура. - 2012. - № 4. - С. 14-20.

16. Е.В. Грязнова. Бытийный статус виртуальной реальности. // Философия и культура. - 2012. - № 12. - С. $35-43$.

17. М. И. Бочаров. Анализ современного состояния системы обучения информационной безопасности в непрерывном образовании. // Национальная безопасность / nota bene. - 2012. - № 1. - C. 120-132.

18. А. В. Царегородцев, А. К. Качко. Один из подходов к управлению информационной безопасностью при разработке информационной инфраструктуры организации. // Национальная безопасность / nota bene. - 2012. - № 1 . - C. 46-59.

\section{References (transliteration):}

1. Urri Dzh. Sotsiologiya za predelami obshchestv: vidy mobil'nosti dlya KhKhI stoletiya /per. s angl. D. Kralechkina; Nats. issled. un-t «Vysshaya shkola ekonomiki»-2012. - S. 10.

2. Vasilenko I. A. Politicheskaya filosofiya: Uchebnoe posobie / I. A. Vasilenko. - M.: Gardariki. 2004.

3. Vladimirova T. V. Razvitie struktur nakopleniya i uskoreniya deviatsii kak uslovie bezopasnosti obshchestva // Zhurnal Sotsiologii i sotsial'noi antropologii-T. XV-№ 2,-2012. - S.129-146;

4. Vladimirova T.V. Setevye kommunikatsii kak novaya «formula spaseniya» sotsial'nogo poryadka // Natsional'naya bezopasnost' / nota bene. 2013. № 2 (25). - S. 371-378. - DOI: 10.7256/2073-8560.2013.02.16.

5. Vladimirova T.V. Informatsionnaya bezopasnost': k metodologicheskim osnovaniyam analiza voprosa // Informatsionnoe obshchestvo № 5, 2012 g. S. 47 - 52;

6. Vladimirova T.V. Informatsionnaya bezopasnost': sotsiologicheskaya perspektiva ponyatiya // Natsional'naya bezopasnost' / nota bene. 2013. № 4 (27). - S. 597-604. DOI: 10.7256/2073-8560.2013.4.7476.

7. Vladimirova T. V. Intensivnost' kommunikatsii praktik novykh mobil'nostei i informatsionnaya bezopasnost' // NB: problemy obshchestva i politiki - 2014. - № 1. - S. 89-111. DOI: 10.7256/2306-0158.2014.1.10918. URL: http://e-notabene. $\mathrm{ru} / \mathrm{pr} / \mathrm{article}$ 10918.html

8. Knorr Tsetina K. Ob' 'ektnaya sotsial'nost': obshchestvennye otnosheniya v postsotsial'nykh obshchestvakh znaniya // Zhurnal sotsiologii i sotsial'noi antropologii. - 2002. - T. V. - № 1. - S. $22-47$.

9. Urri Dzh. Mobil'nosti / per. s angl. A.V. Lazareva, vstup. stat'ya N.A. Kharlamova. - M.: Izdatel'skaya i konsaltingovaya gruppa «Praksis», 2012.

10. Vladimirova T.V. Problema ustoichivosti poryadka kak ugroza bezopasnosti // NB: Natsional'naya bezopasnost'. - 2013. 2. - C. 67-87. DOI: 10.7256/2306-0417.2013.2.590. URL: http://www.e-notabene.ru/nb/article_590.html

11. Bakhtin S.A. Internet-ekonomika - novyi vyzov natsional'noi ekonomicheskoi bezopasnosti: obshchaya kharakteristika // Natsional'naya bezopasnost' / nota bene. - 2012. - 6. - C. 118-122.

12. Vladimirova T.V. K sotsial'noi prirode ponyatiya «informatsionnaya bezopasnost'» // NB: Natsional'naya bezopasnost'. 2013. - 4. - C. 78-95. DOI: 10.7256/2306-0417.2013.4.596. URL: http://www.e-notabene.ru/nb/article_596.html 
13. Vladimirova T.V. Rost «potrebnosti v Neotritsaemom» i bezopasnost' obshchestva // NB: Natsional'naya bezopasnost'. 2013. - № 3. - S.136-157. DOI: 10.7256/2306-0417.2013.3.595. URL: http://e-notabene.ru/nb/article_595.html

14. S.A. Bakhtin Internet-ekonomika - novyi vyzov natsional'noi ekonomicheskoi bezopasnosti: obshchaya kharakteristika // Natsional'naya bezopasnost' / nota bene. - 2012. - 6. - C. 118-122.

15. Tsaregorodtsev A.V., Ermoshkin G.N.. Bazovye printsipy postroeniya dereva tselei informatsionnoi bezopasnosti sredy oblachnykh vychislenii. // Natsional’naya bezopasnost' / nota bene. - 2013. - № 5. - C. 69-79. DOI: .10.7256/20738560.2013.5.9583.

16. A.V. Kostina, G.P. Khorina. Informatsionnaya kul'tura v kontseptsiyakh informatsionnogo obshchestva. // Filosofiya i kul'tura. - 2012. - № 4. - C. 14-20.

17. E.V. Gryaznova. Bytiinyi status virtual'noi real'nosti. // Filosofiya i kul’tura. - 2012. - № 12. - C. 35-43.

18. M. I. Bocharov. Analiz sovremennogo sostoyaniya sistemy obucheniya informatsionnoi bezopasnosti v nepreryvnom obrazovanii. // Natsional'naya bezopasnost' / nota bene. - 2012. - № 1. - C. 120-132.

19. A. V. Tsaregorodtsev, A. K. Kachko. Odin iz podkhodov k upravleniyu informatsionnoi bezopasnost'yu pri razrabotke informatsionnoi infrastruktury organizatsii. // Natsional'naya bezopasnost' / nota bene. - 2012. - № 1. - C. 46-59. 